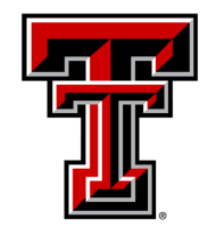

TEXAS TECH UNIVERSITY

Libraries"

\title{
EXPLORING Statistics AND Demography ResourCes ON the WeB
}

\section{The Texas Tech community has made this publication openly available. Please share how this access benefits you. Your story matters to us.}

\begin{tabular}{|l|l|}
\hline Citation & $\begin{array}{l}\text { Quinn, B. A. (1999). Exploring Statistics and Demography Resources } \\
\text { on the Web. Internet Reference Services Quarterly, 4(1), 9-33. } \\
\text { https://doi.org/10.1300/J136v04n01 03 }\end{array}$ \\
\hline Citable Link & $\underline{\text { http://hdl.handle.net/2346/501 }}$ \\
\hline Terms of Use & $\underline{\text { CC-BY }}$ \\
\hline
\end{tabular}


Internet resources for statistics and demography have grown rapidly in recent years, but no place more so than the World Wide Web. The proliferation of available Web sites in these fields has reached the point at which megasites, or lists of lists of resources, have begun to appear.1 Yet despite this explosion of information, it does not appear to be well documented in the professional literature of librarianship. A recent search by the author in the Library Literature database for example, revealed virtually no studies of the multitude of statistics and demography resources now available in cyberspace. Many librarians are probably aware of the existence of Internet versions of $\underline{\text { Statistical Abstract of the United States } 2}$ and the CIA World Factbook 3 but how many realize that these basic resources are just the tip of the iceberg when one considers just how much statistical and demographic data are accessible via the Web?

This mushrooming of resources on the Web can thus be said to have created a twofold need on the part of librarians. First, there is a need to get a basic sense of what is available. Perhaps more importantly, it is important to winnow down the field and identify what appear to be the most useful resources, from the many sites that may be of secondary importance. It is the purpose of this study to try to accomplish both these objectives by not only trying to include only the most important resources, but by also trying to include as many of them as possible.

To accomplish this, the author searched the Web using a variety of different search engines, including multisearch engines, 4 and search terms. These searches produced literally thousands of Web sites and resources, which the author screened for suitability. The criteria for inclusion included such basic considerations as the number of 
links present, how well they were organized, the authority of the source, and how well the links appeared to be maintained.5

One reason why there are so many resources available is that both statistics and demography are interdisciplinary fields. Statistics in particular is a field that is heavily used in many disciplines, including the social sciences, the physical sciences, business, and especially mathematics.6 Indeed, many of the resources currently available on the Web had to be eliminated from consideration because they appeared to be too esoteric in orientation. Sites that seemed to be primarily intended for specialists that were narrow in scope, and filled with professional jargon were kept to minimum. While valuable to the specialist, most librarians would likely find these resources of limited utility in trying to answer statistical questions. A few sites that appeared to be borderline and included both general and technical data were included. The author should make clear however, that this study is primarily limited to resources that are of general utility to the researcher.

Overall, it may be said that using the Web as a source of statistical information offers considerable advantage over traditional paper resources. Generally, the data is more current and can be manipulated and customized at some of the newer, interactive sites. Not only is the ability to create customized data sites an enormous advance over paper resources, but the quality of the graphics is superior as well. Sophisticated threedimensional color graphics are of critical importance in the communication of statistical information, because they facilitate comprehension of complex relationships between multiple variables. Many of the more advanced Web sites now offer these capabilities, 7 which paper resources can seldom match. 
A parallel situation exists for demography. Some demography Web sites now offer powerful interactive features. These are particularly in evidence at points where demography intersects with geography and mapping. For example, at some sites users are presented with maps of a certain region or country. By clicking on an area of interest, the user may be able to view either a graphic depiction of population density, for example, or similar information in tabular form.8 Again, few paper resources can rival this kind of convenience and immediacy.

The possibilities that both hypertext technology and computer graphics offer for the fields of statistics and demography have not been fully developed. In fact, they are only beginning to be realized. It is exciting to see that some of the sites mentioned in this study have devoted a portion of their resources to exploring some of the as yet untapped possibilities that information technology offers these fields. By visiting some of these sites, users can get a glimpse of some of the emerging possibilities, including various kinds of virtual models.9 Anyone with a little imagination can easily envision a point in the not to distant future when users will be able to rapidly construct a customized map or multi-dimensional model from raw data with a few clicks of the mouse.

Until then, the Web sites listed below should prove useful for anyone in need of statistical or demographic information for most regions of the world. If these sites do not themselves provide information, it is likely they will offer a link to a site that does. Even users who may be unable to locate the data they are seeking at one of these sites will be surprised at the amount of statistical and demographic information available on the Web. Hopefully, the sites listed below will serve as a valuable starting point. 
Princeton University Survey Research Center

http://www.princeton.edu/ abelson/index.html

If one had to select a single site that stand out for clarity, simplicity, organization, and overall ease of use, Princeton's Survey Research Center would be it. The Center, which assists faculty and students with planning, conducting, and analyzing surveys, has created a uniquely user friendly site. Major data archives such as the General Social Survey, Gallup Poll results, and the L.A. Times polls can be found here, as well as a number of regional and state polls. There are valuable links to important research organizations and software sites that provide help with creating surveys, conducting focus groups, and processing survey results. This site also provides some extremely helpful links to many other important resources that can be indispensable for survey research, such as air courier services, calendars, dictionaries, phone books, and address finders.10 One can also find an extensive annotated list of academic survey research centers, arranged alphabetically by title. There is an entire subsection of the site devoted to marketing research links that includes the latest developments in the field, employment listings, and a calendar of marketing events. Another subsection consists of links to professional associations that are involved in survey research, including the American Association for Public Opinion Research, The Council of American Survey Research Organizations, and the Marketing Research Association. This is the perfect first stop for anyone who is new to the world of survey research and wants a friendly introduction to a wide array of Web 
resources that will make the research process easier. More experienced researchers will also find much of interest here.

Internet Crossroads in the Social Sciences

http://dpls.dacc.wisc.edu/Internet.html

This site, which is sponsored by the Data and Program Library Service of the University of Wisconsin at Madison, features several colorful graphic image maps that make searching for statistical information and data much easier. Information is divided into boxes, then further subdivided into sections within each box, and one merely clicks on the appropriate section of the box to access the information. If one clicks on the left side of a box, one gets data sets related to a particular topic, and if one clicks on the right side, one gets information about the same topic. The experience is thus a lot like using a remote control on a TV. The information is divided into four boxes: U.S. Government Links, U.S. Non-Gov’t. Links, International Government Links, and International NonGovernment Links. Each box is further subdivided into seven categories: General, Economic/Labor, Education, Geographic/Historical, Health, Political, and Sociological/Demographic. When one clicks on one of these categories, a collection of annotated links appears that are relevant to that topic. The collections of links are not too large, so that one does not feel overwhelmed. Links that do appear have been well chosen, and many are well annotated. The chief advantage of this site is that the graphic image maps make accessing information particularly fast and easy. 
University of Virginia Social Sciences Data Center

http://viva.lib.virginia.edu/socsci/index.html

The most interesting feature of this site is that it is interactive. This means that you can create customized data sets by selecting from a group of variables. The data can then be sorted by various categories and either displayed on a screen or transferred to one's computer via file transfer protocol.11 Although access to some of the data is restricted, there is a wide range of material that is available. It includes both standard statistical reference sources like the County and City Data books, and Uniform Crime Reporting Data, as well as more unusual resources such as the National Bureau of Economic Research Productivity and Trade databases from 1958 to 1991 . Some of the other interactive data sources to be found here include County Business Patterns, National Income and Product Accounts, and the 1990 Census Public Use Microdata Samples. There is also a keyword searchable version of the Standard Industrial Classification Manual. This site also contains a section featuring links to other interactive statistical data sites around the country with annotated descriptions of what kinds of data manipulation are possible at each site. Listed here are American National Election Studies, Bureau of Labor Statistics data, 1990 Census data, Current Population Surveys, the General Social Surveys, and the Panel Study of Income Dynamics. If one is searching for data sets from ICPSR, a list can be found at this site. Another useful option is a collection of links to data centers and libraries in the U.S. In addition to its interactive features, this site is well organized and attractively designed. 
Data on the Net

http://odwin.ucsd.edu/idata/

Based at the University of California at San Diego, Data on the Net boasts a collection of 787 statistics-related sites. Among the resources to be found here are data libraries and data catalogs, as well as more general sources for social science research. A great advantage of this site is that it is keyword searchable. For example, typing in a keyword or phrase such as "crime" will produce an extensive list of Web resources containing crime statistics. You can also browse hundreds of sites that are conveniently arranged into categories, among them "Data," "Data Archives," "Searchable Catalogs of Data," and "Distributors and Vendors of Data." Each of these categories contains extensive collections of links; the "Data" category alone, for example, offers links to 414 sites that have numeric data that one can download. Many of the links feature detailed annotations describing the contents of the site, which makes it especially easy to browse. There is also a section of the site that is devoted to new and updated resources that have recently become available on the Web, and these too are heavily annotated, so that one knows the contents of a site before clicking on the link to it. Also to be found at this site is an annotated guide to ICPSR resources. These resources can be searched by title or keyword, making it unnecessary to scan the entire contents. In addition, Data on the Net features annotated links to 144 social sciences gateway sites that themselves contain extensive collections of links. Taken as a whole, Data on the Net can truly be considered a statistical megasite. 
Statistical Resources on the Web

http://www.lib.umich.edu/libhome/Documents.center/stats.html

The University of Michigan Documents Center has assembled one of the most exhaustive and well organized collections of resources for statistics presently available on the Web. These resources are arranged into broad categories such as "Agriculture," "Business and Industry," "Consumers," "Health," and "Housing." These categories are highlighted by colorful graphic icons that lend this site a user friendly feeling much like Princeton's Survey Research Center site. Contained within each category is an extensive collection of links to statistical sites that are arranged alphabetically be title. Virtually all of the links are briefly annotated in a concise, bullet point style that can be scanned quickly for rapid evaluation of contents. One of the categories is titled "Comprehensive Subjects," and is especially useful because it consists of a collection of links to other statistical sites on the Web, including data archives and both national and international compendiums. More than other sites, Statistical Resources on the Web offers particularly good coverage of international statistical data. Foreign government, economic and trade resources are all well represented at this site, and the collection of links related to foreign government is especially extensive. This site also features statistical data on such hard to find topics as telecommunications, the Internet, and science. There is also a strong set of links to climatological data. Along with Princeton's site, this site is difficult to surpass for both its breadth of resources and its ease of use. It is an excellent first stop for anyone unsure of where to look first for data on a given topic. 
StatLib

http://lib.stat.cmu.edu/

StatLib is a comprehensive index to statistical resources that resides on the Carnegie Mellon University Statistics Department server. The extensive collection of links that can be found at this site are outlined in an index table on the site's homepage. This makes it easy to locate a topic, though it would help if the links were further arranged in alphabetical order. Links that are new or have recently been updated are highlighted for easy location. Some of the statistical data that can be found at this site include a large set of algorithms for applied statistics, a collection of programs for creating designs for statistical experiments, software and extensions for various computer languages such as Genstat, the data archive of the Journal of the American Statistical Association, and much more. This site also features a wide variety of data sets covering a highly eclectic array of topics. These include subjects like backaches, baseball, and biomedical data as well as a number of datasets related to the field of statistics itself, such as log linear models and analysis of variance. Much of the data is related to math and science, and indeed, the overall feeling of the site is that it was created by people with highly technical background for users with similar backgrounds. There is a huge amount of resource material contained at this site, but there is no attempt to present the material in a userfriendly, non-expert mode. It is thus an ideal site for the specialist in math or science who is seeking material of highly technical and possibly esoteric nature, but not for generalists or amateurs without much background in statistics. 
Fedstats

http://www.fedstats.gov/

The United States Federal Government is one of the largest producers of statistical data in the world, with over 70 agencies contributing to the overall output of data.12 The purpose of this site is to provide users with a central repository for the enormous range of statistical material made available by these agencies. The overall design of the site has a very spartan quality with minimal graphics. There is an index to the links contained at the site that is arranged alphabetically A Site Map is also available that details what agencies produce what statistics, which agencies handle regional statistics, the latest press releases from these agencies, and who to contact with specific statistics questions. There is a fairly sophisticated search engine that allows for Boolean searches, that allows you to tailor your search to specific agencies if you prefer. The site has an unusually handy section called "Fast Facts," which provides the latest economic and social indicator statistics from the Federal Statistics Briefing Rooms. Basic economic indicators like production, sales orders, and inventories, output, employment, prices, money, credit and interest rates can be found here, as can international economic statistics. Social indicators like crime, education, health and demography also can be found here. For those with an Adobe Acrobat reader, the entire contents of the Statistical Abstract of the United $\underline{\text { States }}$ can be viewed, as well as specific portions. Fedstats also offers a set of links to additional statistical sites, such as the American Statistical Association and the Committee on National Statistics. It is one of the best sites available for answering questions about broad national economic and social trends. 
Statistics Sites on the Internet

http://www.library.miami.edu/staff/lmc/statpage.html

The Otto G. Richter Library at the University of Miami is home to one of the most impressive collections of statistics-related links available on the Web. Arrayed in a simple, alphabetical, title by title arrangement are over 200 Internet sites, each offering statistics on a particular topic. This extensive list begins with statistics on housing from the U.S. Census Bureau and ends with a link to YouthInfo from the Department of Health and Human Services. In between, one can find links to statistics on the U.S. budget, child care, disability, fertility, income, migration, recreation, and many other topics. One drawback is that the links are not annotated. A high percentage of the sites are taken from various federal agencies. This is an especially useful site if one knows exactly what one is searching for and can zero in on a particular agency or report. The site can be searched by keyword, but the search engine is only capable of searching the library's entire site rather than just the section concerned with statistics Still, the site is valuable if for no other reason than the sheer scope of links it contains, and most of the links appear to be up to date. The site might be helped by arranging the links by subject, so that users who don't have a specific topic in mind can quickly refer to a particular section rather than have to scan the whole site. 
Yale Social Science Data Archive

http://statlab.stat.yale.edu/SSDA/Internet.html

The Social Science Statistical Laboratory at Yale maintains a Web site with extensive resources linking to statistical data, most of which can only be accessed by the Yale community. But the Stat Lab also has a valuable data archive that offers users direct access to numeric data on the Web. The links are extensive enough to require division into several broad index categories, including separate categories for census and noncensus U.S. data, as well as a third category for sources of international data. The links are well annotated, and many include information about the search capability of the site, as well as its contents. There is extensive census material available here, including census maps, CIESIN's Demographic Data Viewer, links to the Government Information Sharing Project, the Census Data Extraction System and Data Ferret System. Non census materials include FRED (Federal Reserve Economic Data), the UC Berkeley 1994 Multi-Investigator Study, the National Election Study 1996, the National Health Interview Survey 1991, and the National Race and Politics Survey 1991. This site also features a number of interesting links to sources of international statistics. These include Foreign Labor Statistics, Social Indicators of Development, Trends in Developing Economies, and the World Crime Survey Data. There are also links to other important statistical sites on the Internet, such as those at the University of Michigan and Ohio State. The Yale Social Science Data Archive is not a sprawling megasite with an overwhelming collection of links, but the ones it does have appear to be well chosen and carefully organized. 
Statistics on the Web

http://www.execpc.com/ helberg/statistics.html

Some of the best sources of statistical information on the Web are personal collections of links assembled by individuals working in the statistics field. This site is a good example. It features a very large collection of links that Clay Helberg has assembled and organized into several categories for easy reference. Among the categories of links that can be found at this site are Professional Organizations, Institutes and Consulting Groups, Educational Resources (Web courses and online texts), Publications and Publishers, Software, Mailing Lists and Discussion Groups, and a list of resources for locating people working in the field of statistics. The site also has a list of links to other important sites on the Web. Within each of these categories, the links are arranged alphabetically by title, and each has a brief annotation. There is a particularly good collection of links related to statistical software packages. This site has a very strong emphasis on professional and applied issues of interest to statisticians and students of statistics, though its overall approach is less technical and somewhat more user friendly than a site like StatLib. It is a great resource for anyone seeking to understand or learn about statistics, but may be less useful as a reference-oriented site that one might consult for specific statistics on a particular social or economic question. 
Statistics and Statistical Graphics Resources

http://www.math.yorku.ca/SCS/StatResource.html

This is another personal statistics page assembled by Michael Friendly of the University of York. It has a technical and professional emphasis similar to Clay Helberg's site, except that it is slightly larger and more comprehensive. Because of its size, Friendly has included a feature that allows you to jump to a particular section of the site without having to scroll down through the entire list of links. The links are divided into subject categories, and include such standard areas as General Statistical Resources, Statistical Associations, Statistics Departments, and separate collections of links for statistical software packages like SAS and SPSS. There are also more specialized collections of links that make this site distinctive. For example, those interested in how statistical data is represented graphically, will find an extensive collection of links to Web sites that feature graphics and data visualization resources. One can find software packages that convert statistical data to graphic form, as well as a host of sites that demonstrate state of the art renderings of numeric data in moving three-dimensional images. At this site, one can also find a particularly good set of links to sites that feature psychological statistics and psychometrics. Another feature of this site is a group of links to various kinds of computerized statistical calculators that will perform statistical operations once numbers are inserted by the user. Those seeking an ample collection of data sets will not be disappointed by this site, as Friendly has many in evidence. This is very much a resource for the specialist in statistics, but it should also prove valuable to students of statistics from a variety of disciplines. 
Dr. B's Wide World of Web Data

http://seamonkey.ed.asu.edu/ behrens/teach/WWW_data.html

This whimsical-sounding site offers the user a sizable collection of links to data archives and repositories from around the world. The site is itself part of a much larger site that is devoted to resources in research methodology and that is sponsored by the College of Education at Arizona State University. Although intended as a site for teaching statistics, the site could also prove quite useful for answering those vexing statistical questions that librarians are sometimes confronted with. This site has a clean simple look to it, which the author apparently intended. Only top level links of information servers are shown to keep clutter to a minimum, and links to numerous files and subdirectories at these sites have been intentionally omitted. Major links are arranged alphabetically by subject and are fully annotated. Some of the more interesting collections of links include drug use and abuse, history, language and literature, and sports. One section of this site consists of a Visualization Theater, in which users can select links to movies that visualize data, and view examples of completed works in various cyber-galleries. There is also a link to interactive and real time data, that enable a user to enter data into online forms which is then computed and the results displayed. This site offers something for both the researcher looking for data on a wide variety of topics, and the student of statistics seeking to learn more about the field. 
The World Wide Web Virtual Library: Statistics

http://www.stat.ufl.edu/vlib/statistics.html

At first glance the main strength of this site appears to be its exhaustive list of links to homepages of departments and schools of statistics around the world. Yet, these many of these homepages contain links to other statistics resources, which makes this a very rich resource. To cite one example among hundreds, the Department of Statistical Science at Cornell has an interesting collection of links that one can access through the departmental homepage. The World Wide Web Virtual Library: Statistics has other strengths as well. One can find a well-chosen selection of data sets that is particularly strong in the life sciences and in the social sciences. There is also a link to the National Institute of Standards and Technology's Statistical Reference Datasets, which allow one to test the accuracy of one's statistical software using reference datasets with pre-verified results. The site also offers a large collection of statistical archives, many of which are educationrelated. There are several electronic textbooks of statistics, for example. Yet there are also links to standard resources such as U.S. Bureau of Labor Statistics and the U.S. Census Bureau. Links to a large group of software resources are available at this site, along with sets of frequently asked questions. This site includes a selection of electronic journals in statistics, though some only provide citations and abstracts rather than the actual full text. The archives of several electronic discussion groups are also to be found here. The site concludes with a set of links to closely related fields such as biostatistics, demography, and geostats, each of which contains many subject related links. 
Yahoo Reference: Statistics

http://www.yahoo.com/Reference/Statistics/

The Yahoo site contains a reasonably good collection of links that covers a broad array of subject areas. The links have clearly been chosen for their value as reference tools, making this one of the best sites for use in answering basic statistical reference questions. All major subject categories are represented at this site, including agriculture, business, crime, education, energy, the environment, and others. An important advantage of this site is its simple, easy to scan layout, with major subject categories being organized in alphabetical order. One special strength of Yahoo is its collection of links on the subject of computers and the Internet. It contains all kinds of statistics on who uses the Internet, how it is used, and why. Another valuable collection of links is to social science data collections around the world. The chief strength of this site is that it covers such a wide variety of subject areas. Except for the computer/Internet category, however, the individual subject collections of links are moderate in size, making this site better suited for general reference work than for more in-depth or specialized kinds of reference searches. Given its particular suitability for answering ready reference kinds of questions, this would be an excellent site to consult early in the course of a search when one is still in the general stages. If one determines that the material is not available at Yahoo, one can then move on to more specialized in-depth sites. 
Social Science Data Archives

http://www.pscw.uva.nl/sociosite/Databases.html

Albert Benschop of the University of Amsterdam has assembled an extremely impressive collection of statistics resources at this site. It is particularly strong in international resources, but the United States is also well represented here. The number of links available here qualifies this as more than a Web page; it is a true megasite. The links are well annotated, and some of them have keyword search capability. For easy reference, the links have been arranged in four basic categories: World Wide, Dutch, European, and Reference. By clicking on one of four buttons, you can go directly to that category without having to scroll through the entire site. Within each category, links are organized alphabetically by title. Links to major statistical sites as well as less well known ones are both well represented. What makes Social Science Data Archives uniquely valuable are its extensive links to international data sites. More countries are represented at this site then most others on the Web. In particular, the selection of European resources is outstanding, making this a site of first choice for anyone interested in continental statistical resources. The international orientation of this site means it has links to sites that would be difficult to find elsewhere, such as the Steinmetz Archive or the World Database of Happiness. An additional feature of this site that is particularly useful is a separate category of links labeled "Reference." It contains many links to other statistical megasites around the world that one can refer to if one is unable to locate information at this site. 
ICPSR Homepage

http://www.icpsr.umich.edu/

No study of Web resources for statistics would be complete without including this site. ICPSR (Inter-university Consortium for Political and Social Research) is located within the Institute for Social Research at the University of Michigan. It is the largest repository of machine readable data in the world, which is why this site is so important. Access to the actual data sets is restricted to members, but the site is valuable to anyone trying to determine what studies have been done on a given topic. Despite the massive number of studies available at this site, they are nonetheless easily accessible due to careful arrangement. For example, one can access a data set by typing in a keyword or string, or by study number. Studies can also be located by searching by title or by principal investigator. Studies are also arranged alphabetically into broad subject categories that allow for easy browsing, and virtually all subjects can be found here. Social, political and legal studies are all well represented in this collection. Some of the best known statistical studies available, such as the General Social Survey, the American National Election Study, and the Panel Study of Income Dynamics are located at this site. There are links that allow you to browse recent additions and the latest updates. New studies are conveniently labeled to stand out from the rest. This site also features a substantial collection of links to other statistics related data sites that are largely based in the United States. This is another reason why this site will be of interest to both ICPSR members and non-members alike. 


\section{IASSIST Homepage}

http://datalib.library.ualberta.ca:80/iassist/

IASSIST (International Association for Social Science Information Service and Technology) is an organization that assists those who work with statistics in their research. Like ICPSR, this is another membership based group, but this site is still worth visiting for non-members who may be interested in learning more about statistical research. For example, IASSIST issues a number of publications and reports designed to educate statistics researchers how to better understand the field, and some of these are available at this site, including the full text of recent issues of IASSIST Quarterly. This quarterly journal features some extremely useful articles on how to conduct better statistics-related research. Also available at this site are the abstracts from recent IASSIST conferences and lengthy bibliographies of books, articles, and conference and workshop proceedings that have been written about the statistical research process. These allow anyone interested in studying the process of conducting statistical research to have a wide array of learning resources readily available for further study. There are also several invaluable Web documents that can be read or downloaded that explain exactly how to conduct research in statistics and include such basic reference tools as thesauri and glossaries that will be very helpful to explain some of the jargon that one encounters when doing statistical research. These documents have been outlined and indexed by subtopic, so that one can zero in on exactly the section of the document that will be most helpful. For anyone who genuinely wishes to understand research in the field of statistics, this site is essential. 


\section{Statistical Data Locators}

http://www.ntu.edu.sg/library/statdata.htm

Statistical Data Locators may well be the most comprehensive set of links currently available on the Web for international statistical information. The site, which is based at Nanyang Technological University in Singapore, uses a geographic classification scheme to organize a multitude of links to statistical information. The site is organized into broad geographic regions, including Asia, Oceania, North America, Europe, Africa, and Latin America. Each of these broad geographic regions is further broken down by countries within that region. For example, "Asia" includes not only China and Japan, but also more obscure countries like Brunei, Myanmar, and Sri Lanka. There are separate links to each country within a region, so that one can simply click on that country to go directly to it. Many of the countries contain links to statistics on trade and economics, health, and politics. The United States is well represented in this international smorgasbord, with numerous links to economic and quality of life statistical sources. But the real value of the site appears to be both the breadth of countries represented, and the amount of detail that is available for many countries. Entire regions that are typically absent from most statistical Web sites can be found here, such as Africa and Oceania. Other countries such as Russia, Egypt and Turkey can be found here as well. A separate and potentially useful section of the site is devoted to international trade and socio-economic data. 


\section{Demography Resources}

The World Wide Web Virtual Library-Demography and Population Studies http://coombs.anu.edu.au/ResFacilities/DemographyPage.html

This is one of the most important demographic sites available on the World Wide Web. With over 155 links to demography and population servers around the world, the WWW Virtual Library is a megasite that is essential for anyone seeking a comprehensive overview of demographic resources on the Web. The site is divided into six categories of links: Demography and Population Studies WWW Servers, WAIS Databases of Interest to Demographers, Demography and Population Studies Gopher Servers, Other World Wide Web Servers of Interest to Demographers, Other WAIS Servers of Interest to Demographers, and other Gopher Servers of Interest to Demographers. It is somewhat puzzling as to why the creators of the site placed such a heavy emphasis on WAIS and gopher, which seem to be archaic technologies. But the collection of links is nevertheless impressive, if one can overlook this odd characteristic of the site. Some of the resources that can be found under Demography and Population Studies WWW Servers include population centers and research institutes, data centers and archives, Web sites of demography journals, academic demography programs and departments, and government institutions involved in population research. The quality of the links is very high, and many of the most important sites in the field are listed here. One particularly interesting 
feature of this site are the large number of sites of related interest to demographers, covering immigration, multicultural studies, geography, economics, and sociology.

\author{
Population Reference Bureau \\ http://www.prb.org/prb/
}

The Population Reference Bureau, a nonprofit educational institution, has created a useful Web site containing an interesting variety of research findings related to population trends and directions. Among the resources that can be found at this site are a 1997 World Population Data Sheet, which contains detailed statistics on world population growth rates. It also provides data on fertility, mortality, contraception, and life expectancy. The data is divided into broad geographic regions (North America, Africa, Asia, etc.) and within each region, by country. The Bureau also has assembled a strong collection of links to other population and demography sites on the Web. The links are divided into government, United Nations, university centers, and population organizations. This is followed by small but unusual collection of links to collections of population resources, which includes the Association of Population Centers, the Population Organizations: Finder's Guide, and several others. An especially valuable feature of this site is its list of Data Web Sites for the 50 States. The list is divided into sites that feature population information for all 50 states and those that contain data for specific states. Along with population data, there is information about the economy, 
lifestyles, resources, and the environment. Resources for individual states are listed alphabetically by state. This site also includes a glossary of population terms.

\section{CIESIN's U.S. Demography Home Page}

http://www.ciesin.org/datasets/us-demog/us-demog-home.html

CIESIN, the Consortium for International Earth Science Information Network, has created an excellent site that includes a section on demography. The CIESIN Homepage features a series of cascading hypertext links to domestic demography resources. The site features an anonymous ftp service for easy retrieval of data files.13 Each of the resources listed is heavily annotated, and include information about who gathered the data, for what purpose, and how the data were obtained. There is separate link that one can click on to find out the primary source of the data. Some of CIESIN's many data resources include the Public Use Microdata Samples, Current Population Survey, National, Economic, Social and Environmental Data Bank, and many others. Every resource includes detailed information about holdings, how the data may be accessed, and other institutional sources that the data may be obtained from, if any. No other site on the Web offers as much descriptive and evaluative information about its data as CIESIN. One never has any doubt about the data they are getting, because layout, design and methodology, and variables have all been spelled out in considerable detail in the descriptive material offered at the site. CIESIN also maintains an archive of over 17,000 census-related files that can be obtained using ftp. The site features data exploration software that allows for 
interactive browsing and analysis of selected files like the Public Use Microdata Samples. CIESIN also features links to sites that offer population simulations and innovative approaches to presenting data.

United Nations Population Information Network (POPIN)

http://www.undp.org/popin.htm

The POPIN Web site is an excellent resource for information about both global and regional population and development trends and issues. For example, a number of the documents from the International Conference on Population and Development, held in Cairo, Egypt in 1994, can be found here. The site also features many documents prepared for the UN Statistical Commission, such as the Demographic, Social, and Migration Statistics. By clicking on a link called "World Population Trends," one can access numerous reports on fertility and mortality around the world, the demographic impact of HIV/AIDS, international migration policies, population trends in developing countries, regional migration flows, and historical population figures. Data is also available on women around the world and urbanization trends. There are links to many other population networks around the world which have been conveniently broken down into broad geographic regions like Africa, Asia, Europe and Latin America. Links that have been added recently are clearly marked. Another useful resource at this site is the POPIN Electronic Library, which contains bibliographies and links to bibliographic databases of population materials from around the world. Anyone who may be looking 
for demographic material or resources about regions outside North America will find a visit to this site worthwhile. It is a first rate source of domestic information as well.

The World Wide Web of Demography http://www.nidi.nl/links/nididemo.html

The World Wide Web of Demography, which was created by the Netherlands Interdisciplinary Demographic Institute, is one of the best sites for international demography information currently available on the Web. The exhaustive collection of links that has been assembled at this site has been divided into six categories: Organizations, Resources, Data, Literature, Conferences, and Software/Models. Each category contains its own extensive collection of links. Indeed, the array of links that are accessible under the category of Organizations is so extensive, it has been subdivided into five geographic subcategories. The links are arranged alphabetically by title within each category. Europe and the Netherlands are well represented, but there are also extensive links to Asia and Oceania. The links to census and survey material are international in scope as well, and include a list of statistical agencies from around the world. This site also includes one of the largest collections of links to population literature to be found on the Web, including an international roster of population and demography journals. There is also an up to date set of links to population conferences around the world. There is also a lengthy and annotated list of software packages available at this site that will prove useful to anyone working in the field of demography. The World Wide Web of 
Demography is a well designed site that features cross links at convenient points to other parts of the site. This is a particularly helpful feature, given the large number of links available.

PSC Library: Resources on the Web http://www.psc.lsa.umich.edu/library/resources.shtml

The Population Studies Center at the University of Michigan has an online library at their Web site that offers over 150 links to demographic resources on the Web. Not only is there a huge amount of resource material available at this site, but it is also extremely well organized. Special links are provided that allow one to jump directly to certain important sites such as the U.S. Census Bureau, so that one does not have to scroll through the entire site. Links are arranged by both subject and format in the form of a grid, so that one see all the possible subjects or formats simultaneously without having to scroll through them. This clever arrangement makes information much easier to access. Besides the standard subjects in population and demography such as fertility, mortality, migration and ethnicity, there are also unexpected categories. One of these, Economics and Poverty, offers separate sets of links to U.S. and international resources. The other two categories, Health and Nuptiality, offer a similar breakdown. In addition to allowing one to search by subject, this site also permits searching by format. Among the available formats are Electronic Indexes and Databases, and Journals and News. It should be noted that some of the resources listed under the databases category are available only to 
University of Michigan students. Despite this limitation, this site is a valuable resource for demography and population research.

\section{SOSIG Demography Homepage}

http://www.sosig.ac.uk:80/roads/subject-listing/World/demog.html

This site is part of the Social Science Information Gateway based in England, and contains a well chosen selection of links to various sites relevant to demography. There are an enormous number of links that SOSIG has collected here, and each is annotated. One can click on the title of the link to get a short description, or one can click on a button to go directly to the site itself. Since the annotations are hidden, the site has a very simple clean look to it. There are many links to U.K. resources such as BIRON, but other regions are well represented at this site. Some of the more interesting links that appear at this site include Asia Studies, which provides socio-economic data for 14 Asian countries. The Commonwealth Yearbook, a site based on the publication, contains demographic and social data on 53 Commonwealth countries that make up the Commonwealth Organization. Another interesting link, called Datahouse, is a United Nations based site that contains both urban and national statistics on human settlements. The Longwave and Social Cycles Resource Centre features online bibliographies and articles that focus on research related to Kondratieff waves and social cycles. A site called Migrants and Refugees: A World on the Move, offers data regarding the global flows of migrating peoples as well as the concerns of host countries. Also featured here 
are links to the Oxford Population Project, the Panel Study on Belgian Households, the Population Data Collection for Mexico site, the Victorian Census Project, and many other interesting resources.

Internet Resources for Demographers

http://members.tripod.com/ tgryn/demog.html

This site has its origins in a paper written by Thomas Gryn called "Internet Resources for Demographers.14 Gryn, who is affiliated with the Department of Sociology at Ohio State University, has assembled a noteworthy set of links. The author has sorted them into six categories for easier access: North American Demography, International Demography, General Demography, Health, Geography, and Other Demography Link Collections. Within each category, many of the links contain brief annotations describing their contents. Some categories have been further divided into subcategories. For example, North American Demography contains a set of links that include general demography pages and a separate subcategory for the homepages of datasets. This is not a megasite featuring hundreds of resources, but the relatively small number of links presented appear to have been carefully selected. Under the category of General Demography, there is a good collection of links to online demographic journals, newsletters and conference papers. There are similarly strong sets of links for anyone seeking epidemiology information or information on visual aspects of demography such as mapping.15 Geographic resources are much in evidence here as well. This is an ideal 
site for someone who does not want to be overwhelmed with links, but still wants some of the best resources from all aspects of demography.

\section{Research Resources for the Social Sciences \\ http://www.socsciresearch.com/rll.html}

This site was created by sociologist Craig McKie, and it is a good resource for almost any aspect of the social sciences, but demography resources in particular are well represented at this site. The main strength of the site is the number of links to be found here. The chief weakness of the site is that the links do not appear to be organized in any particular fashion.16 If one wants to find a particular resource, it is necessary to scroll through the entire list of links. One helpful feature however, is that each of the links is briefly annotated. The links themselves appear to be a highly eclectic collection that include some unusual resources that one is not likely to find at other sites. For example, there is a link to the African Population Database Documentation site, and another to a Rand Corporation document called "Russia's Demographic Crisis." Another very interesting link connects one to a series of frequently asked questions about overpopulation, a site that also includes the current population to the minute. There is a link called "The Right Site," that includes access to 1,000,000 pages of demographic reports. McKie's site has a link to another unusual resource, the Minnesota Historical Census Project, which features 25 samples taken from censuses of the American population from the years 1850 to1990. In addition to these unusual resources, this site also provides links to many of the more 
conventional resources that are available. These include a number of UN resources as well as U.S. Census Bureau data, and resources from leading population agencies in the United States and abroad.

\section{Center for Demography and Ecology}

http://www.ssc.wisc.edu/cde/

The Center for Demography and Ecology, which is based at the University of Wisconsin, has created a Web site that is notable for several reasons. It not only contains useful demographic information, but it presents it in a format that is extremely user friendly. 17 The site utilizes a number of colorful graphic icons to orient the user so that even though the site is large, one never feels lost. The site features a link called Online Information Connections, which connects to another link called Currents, a resource that provides the latest news on population related topics. There are also links to population related sites on the Internet, population related agencies, and to conferences related to population and demography. Those looking for data resources will find links to Wisconsin's own Data Program and Library Service, the National Survey of Families and Households, and the Wisconsin Longitudinal Survey. There is another useful link to the Population Organization Finder's Guide, which can be useful for finding professionals in the field. This site also features an extensive collection of working papers produced by CDE staff and affiliates that cover all aspects of demography. The site provides a bibliography, and 
many of the papers have abstracts that can be viewed as well. Some of the papers are also available in full text via ftp.

\section{A Sociological Tour Through Cyberspace-Demography http://WWW.Trinity.Edu/ mkearl/demograp.html}

Michael Kearl's Web site, A Sociological Tour Through Cyberspace, is one of the best Web sites available in the field of sociology. His demography page, which is accessible through the Web site is similarly a very strong contribution to the field of demography. More so than other demography Web sites, this page is intended as a teaching device for students in the field. It contains a large amount of didactic material about the importance of demography and the significance of demographic theory. The page is extremely user friendly, and is replete with charts and colorful graphics illustrating the concepts Kearl outlines in the text. Links to other important sites are often woven into the text of Kearl's discussion, making each link particularly salient to the reader. Kearl's site serves as more than a primer in demography however, it also contains a large and very well organized collection of links to important demography resources on the Web. The links are organized into several categories: Census Materials, International Data, Population Studies, Immigration, Cities and Urbanization, and Maps. There is a good selection of basic census resources available at this site that will prove useful in answering many basic questions about the U.S. population. This is similarly true for International Resources, though the collection of links here is smaller. One of the best features of this 
site is the collection of maps that Kearl has assembled, which include historical, cultural, and rare maps as well as the standard demographic ones. This site would be an excellent first stop for anyone needing orientation to the general field of demography, yet it is sophisticated enough to interest the professional as well.

Population and Demography Information http://www.pop.psu.edu/Demography/demography.html

This page was created by Penn State's Population Research Institute, and features a large collection of links that have been neatly organized. The large number of links available at this site prompted the authors to create a convenient index. It allows one to go directly to a particular section of the site by clicking on it, rather than have to scroll through the entire collection of links. The site begins with an alphabetical listing of links to the member institutions that make up the Association of Population Centers. These sites are valuable because they often contain links to other demography sites. This is followed by a list of links to North American Demographic and Population Servers, which includes some interesting links not often seen at other demography sites, such as the centers at Indiana and Western Washington universities, and the University of Western Ontario. A separate listing of U.S. Census and other U.S. Data Sources contains links to the census bureau, the National Center for Health Statistics, and ICPSR. There are also separate listings of international organizations and sources of international data, many of which are based here in the U.S. The site concludes with a series of links to sites covering 
related areas such as Research, Methodology, and Statistics. For easy reference, any links that have been newly added are clearly labeled as such with yellow icons.

Census and Demographic Data

http://www.clark.net/pub/lschank/Web/census.html

This page, which was created by Larry Schankman at Mansfield University, is one of the best resources available for demography on the Web. It contains a huge number of links, almost all of which are annotated. The author begins his page with a category called "Starting Points for Demographics." It contains a collection of mega-resources on the Web for initiating one's search. Schankman makes it clear that he considers these sites the best on the Web for demography. The sites are richly annotated, and there are links to relevant subsections of the sites woven into the text of the annotations, much like Michael Kearl has done on his demography page. Since these are megasites, these interwoven links make it extremely easy to pinpoint those sections of a site that are relevant to one's research. It is clear from the annotations that Schankman has explored these sites fully and spent time evaluating their strengths and weaknesses. This saves the browser a great deal of time in a search. Following this list of half a dozen top sites, Schankman has constructed a second category called "Rest of the Best in Demographics." In this category may be found an extensive list of many useful sites, each of which is carefully annotated and evaluated. The text of each annotation is frequently interspersed with links to valuable parts of the site, or links that cross 
reference other sites. This massive collection of links have been alphabetically organized to make browsing easier, but it is the quality of the annotations that make this site stand out from other megasites as uniquely useful.

PopNet

http://www.popnet.org/

PopNet is an excellent resource for information about a wide variety of topics related to population and demography. Although it is sponsored by the Population Reference Bureau, which has its own Web site, PopNet is a significant resource in its own right and deserves to be considered on its own merits. This is a highly graphic site that is easy to use. The many links found at the site are divided into four clickable categories: Organizational Sources, Selected Topics, Clickable World Map, and PopNews. The category Organizational Resources contains a list of links to population related institutions that is so comprehensive, it is further subdivided into government and non governmental organizations, international organizations, and university centers. Links are arranged alphabetically by country. Even obscure countries like Latvia, Malta, and Gaza are listed here, and the links are annotated. The next category, Selected Topics, features many links to Web resources in the areas of demographic statistics, economics, education, environment, gender, policy, and reproductive health. This collection of links is also well annotated. Perhaps the most interesting feature of PopNet is its Clickable World Map. It displays a map of the world broken down into countries, and allows you 
to click on the country and receive a list of region-specific links to information resources.19 PopNet makes searching for demographic data both simple and entertaining.

Florida State University Demographic Navigator http://mailer.fsu.edu/ popctr/demnav.html

The FSU Demographic Navigator is an attractive site that incorporates a nautical theme into the design of its Web page. The page uses frames in an unusual layout that allows one to search remote sites while still maintaining the FSU Navigator page within view.20 The links that have been collected at this site are broken down into three general categories. The first, Links to Working Papers, features a series of links to research papers on population and demography that have been completed at various population centers around the world. Some of these sites include abstracts, and a few even include the full text of the papers. Most of the population centers listed are based here in the U.S., and include major institutions like Indiana University, the University of North Carolina, Penn State, the University of Washington, and the University of Wisconsin. The second general category of resources, Links to Other Population Centers, contains a series of links to population centers both in the U.S. and abroad, and lists them alphabetically. There are some interesting links in this collection, such as the University of Costa Rica's Central American Population Program, and the University of Chulalongkorn's Institute of Population Studies, based in Thailand. The Demographic 
Navigator also features a third category of links, to online journals in demography and population studies. This collection includes major journals like American Demographics and Population Index. Some of these journals make the full text available online, and a few allow keyword searching of the text.

Links of Interest to Demographers http://www.lshtm.ac.uk/eps/cpslinks.htm

Sponsored by the London School of Hygiene of the University of London, this site features a large array of links to many different demography and population resources around the world. For the convenience of the browser, the links have been sorted into a number of different categories. One category, Journals, Newsletters and Books, features a lengthy list of journals in the field, with helpful annotations indicating what parts of the journal are available for viewing, such as table of contents, abstracts, etc. Titles that have been added recently are designated by special icons. The full text of some reports is also available, such as the State of the World Population 1996, and The State of the World's Children 1997. There is another category of links following the journals that is simply titled "Information," and appears to be a collection of miscellaneous resources covering various aspects of demography. This site also includes links to many data archives around the globe, and includes a map of social science data archives worldwide. Also available at the site are various software packages for use in manipulating data. There is a small but international list of population related societies and organizations as 
well as a much larger list of population research centers from all parts of the globe. Lists of government agencies, foundations and international population organizations are also available here. The site concludes with a list of other demography Web sites and a white pages for locating population professionals. 21

\section{$\underline{\text { Conclusion }}$}

This study has been a pilot attempt to explore what kinds of statistics and demography resources are available on the World Wide Web. Although the resources currently available are a highly diverse group of sites that resist easy characterization, it is nonetheless possible to make some generalizations. For example, there are many more statistics than demography resources presently available, perhaps because of the interdisciplinary nature of statistics. Many of these statistics resources tend to be more highly specialized in nature than the demography resources.

Looking more closely at these resources, it appears that the Web contains more data and datasets than many librarians probably realize. These data resources run the entire gamut of subjects, from "happiness" to data on the use of the Internet itself. Much of the data is produced by various government agencies from countries around the world, many of whom now maintain Web sites.22 The Web, however, is more than a repository for statistical data. It is also a valuable source of information about the craft of statistics itself, including many aspects of research, design, and analysis. Indeed, it is possible to 
learn a great deal about the discipline of statistics by utilizing the growing number of Web-based courses and texts that are becoming available online. 23

It is also possible to make a few concluding generalizations about the resources themselves. By far the United States, and in particular United States government agencies, have contributed the most in terms of data. Data about broad economic and social trends here in the U.S. is thus easiest to find. Well developed, industrialized countries like Canada, Britain, France, and Germany have also made significant amounts of data available, although less so than the U.S. In contrast, smaller developing countries have a much weaker presence on the Web, making it much more difficult to find detailed statistical and demographic information about them. Although a growing number are now online, it appears many have only recently constructed sites that, hopefully, will offer more data in years to come. 
$\underline{\text { Notes }}$

1) Internet/Web Growth Exponential As Usual,” Searcher 5(1997): 54-5.

2) U.S. Bureau of the Census. Statistical Abstract of the United States: 1997. [URL: http://www.census.gov/prod/www/abs/cc97stab.html].

3) Central Intelligence Agency. The World Factbook: 1996. [URL: http://www.odci.gov/cia/publications/nsolo/wfb-all.htm].

4) Greg R. Notess, "Internet 'Onesearch' with the Mega Search Engines," Online 20 (1996): 36-39.

5) Scott D. Brandt, "Evaluating Information on the Internet," Computers in Libraries 16 (1996): 44-46.

6) R. Gnanadesikan, "Looking Ahead: Cross-Disciplinary Opportunities for Statistics," The American Statistician 44 (1990): 121-125.

7) M. Jern, "Visual Data Mining on the Web," Software World 28 (1997): 7-8.

8) J. A. Dykes, "Exploring Spatial Data Representation with Dynamic Graphics," Computers and Geosciences 23 (1997): 345-370.

9) J. Keiper and T. Wickham Jones, "Designing Tools for Visualization and Optimization,” ORSA Journal on Computing 6 (1994): 273-277.

10) James A. Dyer, "The Art and Science of Survey Research," in Americans View Crime and Justice: A National Public Opinion Survey, eds. Timothy J. Flanagan and Dennis R. Longmire (Thousand Oaks, Ca.: Sage, 1996): 159-169.

11) R. Webster West and W.W. Piegorsch, "Interactive Statistics on the Internet: Applications in Environmental Biology," Computing Science and Statistics 28 (1996): 439-444. 
12) Anne L. Buchanan, "A Walk Through the Obscure with Federal Economic Statistics," The Reference Librarian 48 (1995): 167-77.

13) David R. Lankes, “Telnet and FTP: the Internet's Forgotten Heroes,” Information Searcher 7 (1995): 16-19.

14) Thomas Gryn, “Internet Resources for Demographer's,” Population Index 63 (1997): $189-204$

15) S. Geer, "Mapping the Future: Geographic Information Systems," Management Computing 14 (1991): 68-70.

16) James R. Rettig, "Beyond "Cool”-Analog Models for Reviewing Digital Resources on the Web," Online 20 (1996): 52-54.

17) Wilfred F. Lancaster. What is User Friendly? (Urbana, IL.: University of Illinois, 1987).

18) Dorothy F. Byers and Lucy Wilson, "The Web as a Teaching Tool," in National Online Meeting: 1996 (Medford, N.J.: 1996): 31-36.

19) M.J.Kraak and R. van Driel, "Principles of Hypermaps," Computers and Geosciences 23 (1997): 457-64.

20) Greg R. Notess, “Negotiating Netscape’s Frames,” Online 20 (1996): 65-66.

21) Aggi W. Raeder, "People Locators on the Web: Finding and Being Found," Searcher 4 (1996): 48-50.

22) Peggy Jobe, "Researching Countries on the Internet," Colorado Libraries 21 (1995): $50-51$.

23) Rama Vishwanatham, Walter R. Wilkins, and Thomas Jevec, “The Internet As a Medium for Online Instruction," College and Research Libraries 58 (1997): 433-444. 